\title{
Rapid and cost-effective nutrient content analysis of cotton leaves using near-infrared spectroscopy (NIRS)
}

\author{
Jeremy A Prananto ${ }^{\text {Corresp., }}{ }^{1}$, Budiman Minasny ${ }^{1}$, Timothy Weaver $^{2}$ \\ ${ }^{1}$ School of Life and Environmental Sciences, The University of Sydney, Sydney Institute of Agriculture, Sydney, New South Wales, Australia \\ 2 CSIRO Agriculture and Food, Myall Vale, New South Wales, Australia \\ Corresponding Author: Jeremy A Prananto \\ Email address: jayyprananto9@gmail.com
}

The development of portable near-infrared spectroscopy (NIRS) combined with smartphone cloud-based chemometrics has increased the power of these devices to provide real-time in-situ crop nutrient analysis. This capability provides the opportunity to address nutrient deficiencies early to optimise yield. The agriculture sector currently relies on results delivered via laboratory analysis. This involves the collection and preparation of leaf or soil samples during the growing season that are time-consuming and costly. This delays farmers from addressing deficiencies by several weeks which impacts yield potential; hence, requires a faster solution. This study evaluated the feasibility of using NIRS in estimating different macro- and micronutrients in cotton leaf tissues, assessing the accuracy of a portable handheld NIR spectrometer (wavelength range of 1350-2500 nm). This study first evaluated the ability of NIRS to predict leaf nutrient levels using dried and ground cotton leaf samples. The results showed the high accuracy of NIRS in predicting essential macronutrients $\left(0.76 \leq \mathrm{R}^{2} \leq 0.98\right.$ for $\mathrm{N}, \mathrm{P}, \mathrm{K}, \mathrm{Ca}, \mathrm{Mg}$, and $\left.\mathrm{S}\right)$ and most micronutrients ( $0.64 \leq \mathrm{R}^{2} \leq 0.81$ for $\mathrm{Fe}, \mathrm{Mn}, \mathrm{Cu}, \mathrm{Mo}, \mathrm{B}, \mathrm{Cl}$, and $\mathrm{Na}$ ). The results showed that the handheld NIR spectrometer is a practical option to accurately measure leaf nutrient concentrations. This research then assessed the possibility of applying NIRS on fresh leaves for potential in-field applications. NIRS was more accurate in estimating cotton leaf nutrients when applied on dried and ground leaf samples. However, the application of NIRS on fresh leaves was still quite accurate. Using fresh leaves, the prediction accuracy was reduced by $19 \%$ for macronutrients and $11 \%$ for micronutrients, compared to dried and ground samples. This study provides further evidence on the efficacy of using NIRS for field estimations of cotton nutrients in combination with a nutrient decision support tool, with an accuracy of $87.3 \%$ for macronutrients and $86.6 \%$ for micronutrients. This application would allow farmers to manage nutrients proactively to avoid yield penalties or environmental impacts. 


\section{Rapid and cost-effective nutrient content analysis of cotton}

2 leaves using near-infrared spectroscopy (NIRS)

3 Jeremy Aditya Prananto ${ }^{1}$, Budiman Minasny ${ }^{1}$, Timothy Weaver ${ }^{2}$

${ }^{1}$ School of Life and Environment, The University of Sydney, Sydney Institute of Agriculture,

6 Sydney, New South Wales, Australia

$7 \quad{ }^{2}$ CSIRO Agriculture and Food, Myall Vale, New South Wales, Australia

8

9

10

11

12

13

14

15

Corresponding Author:

Jeremy Aditya Prananto ${ }^{1}$

Email address: jayyprananto9@gmail.com

\section{Abstract}

The development of portable near-infrared spectroscopy (NIRS) combined with smartphone cloud-based chemometrics has increased the power of these devices to provide real-time in-situ crop nutrient analysis. This capability provides the opportunity to address nutrient deficiencies early to optimise yield. The agriculture sector currently relies on results delivered via laboratory analysis. This involves the collection and preparation of leaf or soil samples during the growing season that are time-consuming and costly. This delays farmers from addressing deficiencies by several weeks which impacts yield potential; hence, requires a faster solution. This study evaluated the feasibility of using NIRS in estimating different macro- and micronutrients in cotton leaf tissues, assessing the accuracy of a portable handheld NIR spectrometer (wavelength range of 1350-2500 $\mathrm{nm}$ ). This study first evaluated the ability of NIRS to predict leaf nutrient levels using dried and ground cotton leaf samples. The results showed the high accuracy of NIRS in predicting essential macronutrients $\left(0.76 \leq \mathrm{R}^{2} \leq 0.98\right.$ for $\mathrm{N}, \mathrm{P}, \mathrm{K}, \mathrm{Ca}, \mathrm{Mg}$, and $\left.\mathrm{S}\right)$ and most micronutrients $\left(0.64 \leq \mathrm{R}^{2} \leq 0.81\right.$ for $\mathrm{Fe}, \mathrm{Mn}, \mathrm{Cu}, \mathrm{Mo}, \mathrm{B}, \mathrm{Cl}$, and $\mathrm{Na}$ ). The results showed that the handheld NIR spectrometer is a practical option to accurately measure leaf nutrient concentrations. This research then assessed the possibility of applying NIRS on fresh leaves for potential in-field applications. NIRS was more accurate in estimating cotton leaf nutrients when applied on dried and ground leaf samples. However, the application of NIRS on fresh leaves was still quite accurate. Using fresh leaves, the prediction accuracy was reduced by $19 \%$ for macronutrients and $11 \%$ for micronutrients, compared to dried and ground samples. This study provides further evidence on the efficacy of using NIRS for field estimations of cotton nutrients in combination with a nutrient decision support tool, with an accuracy of $87.3 \%$ for macronutrients and $86.6 \%$ for micronutrients. This application would allow farmers to manage nutrients proactively to avoid yield penalties or environmental impacts. 


\section{Introduction}

Cotton production in Australia is one of the most important agricultural industries in terms of export. Approximately $99 \%$ of Australia's cotton is exported, contributing two billion dollars towards the Australian economy in 2018 (Cotton Australia, 2018). One of the most challenging issues currently impacting the industry is inefficient nutrient management (Beegle et al., 2000; Dobermann, 2007; Ali et al., 2008). For instance, the timing of nitrogen $(\mathrm{N})$ application at crucial physiological stages determines the crop development, yield potential, and fibre quality (Read et al., 2006; Rochester, 2011; Yang et al., 2011). However, farmers and their consultants tend to frequently over-supply $\mathrm{N}$ to avoid a yield penalty from $\mathrm{N}$ deficiency. Oversupplying $\mathrm{N}$ can also have a negative impact on cotton, i.e., environmental through nitrous oxide emissions and economical (Deutscher et al., 2001; Rochester, 2011). Thus, a more strategic management of $\mathrm{N}$ and other nutrients is desirable to improve the overall yield, quality, and income of cotton production, while reducing negative environmental impacts.

Efficient crop nutrient management relies on the ability to balance the nutrient demand of crops with the supply from the soil (Van Noordwijk and Cadisch, 2002; Fageria and Baligar, 2005; Ulissi et al., 2011). It is important to note that this crop nutrient demand is dynamic, as it changes in terms of both quantity and quality throughout the season (Hallikeri et al., 2010). Ensuring adequate nutrients are available in an accessible form during key stages of crop growth is crucial in determining the overall yield and fibre quality in cotton (CRDC and CottonInfo, 2019).

Split application is one management strategy that divides nutrient application, for example, $30 \%$ before sowing and $70 \%$ allocated during crucial physiological periods (Hallikeri et al., 2010). This strategy improves the nutrient use efficiency by allowing nutrients to be adjusted and allocated more efficiently to meet the crop's dynamic nutrient demand (Hallikeri et al., 2010). To properly execute this split application strategy, the ability to monitor the crop's nutrient status during the season would be integral. Knowing the nutrient status of the crop in real-time would provide growers with the ability to adjust their nutrient applications at critical stages of cotton crops more accurately and effectively (Tarpley et al., 2000; Samborski et al., 2009).

Current methods of monitoring and determining the nutrient status or demand for cotton crops are based on soil and less often on leaf/petiole nutrient analysis. One of the issues with soil analysis is it only provides the overall nutrient content present in the soil (Houba et al., 1996); however, it does not provide information on the plant available nutrients due to different nutrients existing in different forms and availability to the plant. For example, 
80 total nitrogen is commonly measured in soil analysis; whereas only a small portion of total 81 nitrogen, mainly nitrate is available for plants (Miley et al., 1990). Moreover, this nutrient 82 monitoring method requires time-consuming and expensive laboratory analysis. Due to 83 the significant amount of time between sampling and when results are obtained, farmers 84 are forced to be reactive in their nutrient management. Due to the dynamic nature of the 85 delayed become irrelevant. Thus, for split application in cotton crops to be more effective, a monitoring method that can provide real-time analysis of the nutrient status of crops is desirable.

Handheld near infrared spectroscopy (NIRS) technology is an emerging technique that can potentially provide a rapid, cheaper, and more efficient solution to the time-consuming and expensive laboratory analysis (García-Martínez et al., 2012; van Maarschalkerweerd and Husted, 2015). These handheld devices utilise a design that incorporates a miniaturised spectrometer making them more compact. While research-grade portable Vis-NIR (visible to near infrared) instruments have been proven as the standard in measurement, the use of emerging miniaturised spectrometer would offer value to growers and consultants.

The most crucial advantage of NIRS is that it can provide real-time in-situ analysis of the plant nutrient status. This would allow growers to be more proactive and efficient in their nutrient management. Therefore, it would be beneficial to study the potential use of a portable NIR instrument for estimating in-situ plant nutrient status.

NIRS has been used extensively in the agriculture industry, including grain quality analysis, dry matter or sugar analysis of fruits (e.g., grapes, avocados, or mangoes), forage quality analysis, and soil analysis (e.g., Peng et al., 2015; Tang et al., 2020; Ng et al., 2019). There are few published results in the literature that have explored the use of NIRS for the nutrient analysis of various plants such as mustards (Martínez-Valdivieso et al., 2019), sorghum, oat, and corn (Savi et al., 2019), wheat and barley (Zerner and Parker, 2019), vine and grape berries (Cuq et al., 2019), and peach (Dedeoglu, 2020). The use of NIRS for the determination of plant nutrient status in cotton is limited and was reported in a study by Tarpley et al. (2000) in the United States of America. Therefore, it would be essential to conduct a study on the application of NIRS in estimating various macro- and micronutrients in cotton crops, which can potentially be used as a tool that can provide a real-time and accurate nutrient status of cotton crops for nutrient management.

Most studies on utilising NIRS in estimating the nutrient status of leaves were done on dried and ground leaf samples, which requires an extensive amount of labour and time 
120 (drying and grinding the sample) (Galvez-Sola et al., 2015). The ability to measure the 121 nutrient status of fresh leaves in real-time and in-field would be highly desirable. Hence, 122 it would be useful to analyse the feasibility of applying NIRS on fresh leaves.

123

124

125

126

127

128

129

130

131

132

133

134

135

136

137

138

139

140

141

142

143

144

145

146

147

148

149

150

151

152

153

154

155

156

157

158

This study evaluated the performance of NIRS in estimating important macro- and micronutrients of cotton leaf tissues using an emerging low-cost handheld NIR spectrometer. Additionally, this study developed a NIRS model from fresh leaves which has the potential to be used in field conditions. The accuracy of these fresh leaf models was compared to models built using dried and ground leaves. Lastly, this study assessed the effectiveness of using NIRS predicted leaf nutrient status information on nutrient decision support tools.

\section{Materials \& Methods}

\subsection{Cotton leaf near infrared (NIR) spectra acquisition}

NIR reflectance spectra were collected from 375 cotton leaf samples sourced from the Australian Cotton Research Institute (ACRI), Myall Vale. The leaves were collected from two recently released Bollgard $₫ 3$ cotton varieties, Sicot 714B3F and Sicot 746B3F.

The handheld NIR spectrometer (PhoneLab ${ }^{\mathrm{TM}}$ ) used in this study comprises a single photodetector, $1300-2500 \mathrm{~nm}$ wavelength range (NIR range) with a $16 \mathrm{~nm}$ resolution manufactured by Si-Ware Systems similar to the Neospectra system used by Tang et al. (2020). The wavelength accuracy is $\pm 1.5 \mathrm{~nm}$ with repeatability of $\pm 0.15 \mathrm{~nm}$. The spectrometer is developed based on a semiconductor Micro Electro-Mechanical Systems (MEMS) microfabrication techniques (Figure. 1A, 1C). It uses a $3.3 \mathrm{~V}$ power supply, which powers three configurable lamps with a fibre optic light source. The light beam collects at a diameter of $2.5 \mathrm{~mm}$. The spectrometer uses the ceramic reflector with one side glazed 99AL2O3, ODD22*3mm white reference. This spectrometer is an emerging low-cost $(\sim \$$ $2,500)$ NIR instrument, weigh less than $0.5 \mathrm{~kg}$, with a dimension of $7.5 \times 5 \times 5 \mathrm{~cm}$.

\section{[Figure. 1]}

Spectrometers were warmed up for 30 minutes before use to reduce noise in the spectra. The spectrometers were calibrated using a white reference at the beginning of the scans and after every three scans. All scans were conducted with an aluminium foil background to maintain a consistent depth of penetration. NIR reflectance spectra were taken at three different sample conditions;

a. Fresh and intact leaves 
159

160

161

162

163

164

165

166

167

168

169

170

171

172

173

174

175

176

177

178

179

180

181

182

183

184

185

186

187

188

189

190

191

192

193

194

195

196

197

The first set of NIR reflectance spectra were collected from fresh leaves that were still intact on the plants inside a glasshouse (see supplementary Figure 1A). The glasshouse microclimate mimicked an ideal growing condition of cotton in the field, with a temperature between $30-35^{\circ} \mathrm{C}$ and relative humidity of $60-70 \%$. The NIR scans were conducted on 115 samples, where each sample comprised of two leaves from the same plant. The NIR scans were administered at the base of the leaf close to the main veins at three replicates (different positions) for each leaf, which resulted in a total of 6 scans per sample. Leaf samples were collected from different parts of the plant to optimise the variation in nutrient content, as some nutrients such as $\mathrm{N}$ are quite mobile within the plant (Marschner, 2011).

\section{b. Fresh and removed leaves}

After the first set of scans, the leaves were removed from the plants (see supplementary Figure. 1B). The leaves were then left in room condition $\left(25^{\circ} \mathrm{C}\right)$ for 1 2 hours to simulate a situation where scanning at the field is not possible, in which an analyst would remove the leaves and scan them in a more controlled environment. The leaves were scanned using the same protocol as the fresh and intact scans with 6 replicates for each sample. For fresh and removed scans, there were an additional 114 samples that were scanned in the previous summer 2019.

\section{c. Dried and ground leaves and petioles}

After the second set of scans, each sample of two leaves was oven-dried at $60^{\circ} \mathrm{C}$ until constant weight to ensure moisture was removed from the leaves. The petioles were separated from the leaves. Then, both leaf and petiole samples were ground passed through a $0.25 \mathrm{~mm}$ sieve using the FOSS Cyclotec ${ }^{\mathrm{TM}} 1903$ grinder. The dried and ground leaf samples (supplementary Figure. 1C) weighing approximately 2.5 to 5 grams depending on the leaf size were spread on the aluminium foil and flattened to a thickness of 2-3 $\mathrm{mm}$ for leaf samples and a minimal of $1 \mathrm{~mm}$ thickness for petiole samples, fully covering the NIR sensor. The dried and ground leaf and petiole samples were then scanned three times at different positions to ensure a representative reading. For dried and ground samples, there were an additional 114 samples that were scanned in the previous summer 2019 and another 146 samples that were collected from the previous growing season (2017/2018).

Scanning of dried and ground leaf samples started from March 2019, whereas the fresh leaf samples were scanned during winter in July 2019. As it was not possible to scan all leaves under fresh and intact or fresh and removed conditions (due to time constraint and growing season), only 115 cotton leaf samples were scanned under three conditions (dried and ground, fresh and removed, fresh and intact), and only 115 leaf samples had 
198

199

200

201

202

203

204

205

206

207

208

209

210

211

212

213

214

215

216

217

218

219

220

221

222

223

224

225

226

227

228

229

230

231

232

233

234

235

petiole data. The reflectance spectra trend of cotton leaves at different sample preparation can be seen in Figure. 2.

[Figure. 2]

\subsection{Nutrient analysis of cotton leaf}

The dried and ground leaf and petiole samples were analysed in a commercial laboratory (CSBP Plant and Soil Analysis Laboratory) to obtain nutrient data. Nutrients that were assessed included macronutrients (leaf and petiole total Nitrogen (total $N$ ), nitratenitrogen (nitrate-N), phosphorus $(P)$, potassium $(K)$, sulfur $(S)$, calcium $(\mathrm{Ca})$, and magnesium (Mg)) and micronutrients (molybdenum (Mo), manganese (Mn), zinc $(\mathrm{Zn})$, iron $(\mathrm{Fe})$, sodium $(\mathrm{Na})$, chloride $(\mathrm{Cl})$, boron $(\mathrm{B})$, and copper $(\mathrm{Cu})$. The methods for each nutrient are listed below:

- Total nitrogen (total N) was measured using Method 9G2 of Rayment and Lyons (2012), which used the Dumas high temperature combustion method (LECO CN 925 analyser).

- Nitrate-N and $\mathrm{Cl}$ were extracted using deionised water. Extracted nitrate was reduced to nitrite via copperised cadmium column and measured colourimetrically. The extracted $\mathrm{Cl}$ was reacted with mercuric thiocyanate, which released the thiocyanate ions that was reacted with ferric ions and measured colourimetrically.

- $\mathrm{P}, \mathrm{K}, \mathrm{Ca}, \mathrm{Mg}, \mathrm{Cl}, \mathrm{Na}, \mathrm{Fe}, \mathrm{Zn}, \mathrm{B}, \mathrm{Mn}$, and $\mathrm{Cu}$ were extracted using hydrogen peroxide and nitric acid solution and analysed via the ICP (Inductively coupled plasma) spectroscopy (McQuaker et al., 1979).

- Mo was digested using hydrogen peroxide and nitric acid mixture and the digests were read using ICP-MS (Inductively coupled plasma mass spectroscopy) (McQuaker et al., 1979).

The nutrient data of the cotton leaves from the commercial laboratory analysis are shown in Table 1.

[Table 1]

\subsection{Spectra pre-processing}

The raw spectra (Figure 1) were processed prior to the multivariate calibration analysis to remove any significant noise. All spectra processing, modelling, and data analyses were performed using $\mathrm{R}$ statistical software. The spectra pre-treatments were kept consistent across all treatments to gain true comparisons of the different treatments (e.g., spectra wavelength/device used and sample treatment). First, the reflectance spectra 
236 from each sample (6 replicates per sample for fresh leaves, 3 replicates per sample for 237 dried and ground leaves) were averaged. The averaged reflectance spectra were 238 allocated to standard wavelength positions with $5 \mathrm{~nm}$ spacing via spline interpolation 239 using the 'resample' function from the prospectr package in R (Stevens et al., 2015). 240 Then, the $5 \mathrm{~nm}$ resolution spectra were subjected to a detrending function to remove 241 scattering effect using the 'detrend' function in the prospectr package (Stevens et al., 242 2015), where the spectra were normalised using the SNV (Standard Normal Variate) 243 transformation followed by fitting a second-order polynomial model. The residuals of the 244 trend were utilised as a detrended spectra.

245

246

\subsection{Establishing calibration models}

248

The pre-processed reflectance spectra (section 2.3) and the nutrient analysis data (section 2.2) were used to build the calibration models. Models were built for each of the

249 nutrients, and three models were calibrated using leaf reflectance spectra at three sample

250 conditions (i.e., fresh and intact leaves, fresh and removed leaves, and dried and ground

251 leaves).

252

253

Calibration models were built using the Cubist regression tree (Kuhn and Johnson, 2013).

254 Cubist is a rule-based model commonly used in analysing NIR spectra data in soil studies

255 (Peng et al., 2015; Tang et al., 2020; Ng et al., 2020). Cubist creates a tree model by 256 splitting the data based on the selected reflectance wavelength to minimise the error of prediction. Within each split (subset of the data), Cubist fits a linear model using spectra as predictors. This results in a set of "if-then" rules where within each rule, a linear model of spectra model is prescribed (Kuhn and Johnson, 2013). The Cubist regression model was used in this study as it was shown to provide comparable or better calibration compared to the conventional partial least squares regression technique (Tang et al., 2020, See also Supplementary Information).

263

264

The dataset was split randomly into $75 \%$ for calibration data and the other $25 \%$ was used 265

266

267 as validation data to assess the predictive accuracy of the model. Accuracy parameters of the models included: coefficient of determination $\left(R^{2}\right)$, Lin's concordance, root mean square error (RMSE), and bias as described in Nicolai et al. (2007). The random 75:25 data split and calibration processes were repeated 50 times to gain an average measurement of the accuracy parameters.

270

\subsection{Statistical Analysis}

272 The accuracy of the prediction was assessed using $\mathrm{R}^{2}$ and RMSE. The $\mathrm{R}^{2}$ was calculated 273 using Eq.1 with $n_{p}$ the number of objects used in the calibration or validation, $\overline{y_{i}}$ the 
274 average of al the observation, and $\hat{y}_{i}$ and $y_{i}$ the predicted and measured value of the $t^{\text {th }}$ 275 observation respectively, shows the proportion of the variance of the calibration or 276 validation dataset explained by the model and RMSE was calculated using Eq. 2 277 measures the goodness of fit of the model (Nicolai et al., 2007).

$$
\begin{aligned}
& R^{2}=1-\frac{\sum_{i=1}^{n_{p}}\left(\hat{y}_{i}-y_{i}\right)^{2}}{\sum_{i=1}^{n_{p}}\left(\overline{y_{i}}-y_{i}\right)^{2}} \\
& R M S E=\sqrt{\frac{\sum_{i=1}^{n_{p}}\left(\hat{y}_{i}-y_{i}\right)^{2}}{n_{p}}}
\end{aligned}
$$

Eq. 2

278 The statistical distribution of the $R^{2}$ values from the 50 repetitions of the calibration and

279

280

281

282

283

284

285

286

287

288

289

290

291

292

293

294

295

296

297

298

299

300

301

302

validation predictions of the models constructed from the NIR leaf spectra in predicting macro- and micronutrient will be portrayed as a boxplot for comparisons. First, the statistical distribution of the average $R^{2}$ values of the models calibrated from the NIR (1350-2500) in predicting all macro- and micronutrients on the calibration and validation datasets were compared. These models were developed from the 375 dried and ground leaf samples. Dried and ground leaf samples were used as standards because NIR reflectance can be affected by moisture and particle size (Ludwig and Khanna, 2001). In this way, we can assess the accuracy of NIR spectrometer without the effect of external conditions (moisture, temperature, etc.).

The validation accuracy parameter, RMSE from the 50 repetitions, was then used to compare the NIR models using a paired t-test analysis $(\alpha=0.01)$ to assess the significance of the different leaf treatments. The RMSE was chosen to represent the quality of the calibrations because it portrays the goodness of fit of the calibrations, where a lower RMSE indicates a calibration with higher accuracy.

Finally, important wavelengths used by the Cubist models for the prediction of the different nutrients were extracted to analyse the relationship between the NIR reflectance spectra and the corresponding nutrient content. The three most important wavelengths used in the 50 iterations of the Cubist model to estimate each nutrient were recorded and displayed in a density plot to assess the importance of different regions of the spectra in estimating the assessed nutrients.

\subsection{Application in nutrient decision support system analysis}


303 NutriLOGIC is a commonly used decision support tool in the Australian cotton industry

304

305

306

307

308

309

310

311

312

313

314

315

316

317

318

319

320

321

322

323

324

325

326

327

328

329

330

331

332

333

334

335

336

337

338

339

340

that can aid in the identification of deficient and excessive levels of various macro- and micronutrients most commonly used for $\mathrm{N}$ management (Deutscher et al., 2001). NutriLOGIC uses an algorithm that categorises the nutrient levels of a cotton plant into three levels: (1) High, (2) Normal, and (3) Low based on the developmental stage of the crop and its current nutrient status. This would help farmers decide whether any fertiliser application is required.

A total of 25 samples were randomly selected from ACRI in Myall Vale to test the efficacy of the fresh leaf NIRS models when used in the NutriLOGIC system. The measured and predicted concentrations of each nutrient were inserted into NutriLOGIC, where each nutrient for each sample will be given a category. The resulting analysis of $N, P, K, S, C a$, $\mathrm{Mg}$ were grouped as macronutrients and $\mathrm{Na}, \mathrm{Zn}, \mathrm{Fe}, \mathrm{Cu}, \mathrm{Mn}, \mathrm{B}$ were grouped as micronutrients. The analysis of both macro- and micronutrients status were compared, and the categorisation error of the predicted nutrient status were assessed to determine whether the accuracy of fresh leaf models is acceptable in practice.

\section{Results}

Section 3.1 compares the calibration and validation prediction accuracy of models calibrated from the NIR spectra of dried and ground leaf samples in predicting leaf macroand micronutrients. Sections 3.2 and 3.3 detail the performance of the NIRS models in predicting macronutrients and micronutrients, respectively. Section 3.4 compares the prediction accuracy of calibrations constructed from leaves under different sample treatments or conditions. Section 3.5 demonstrates the effectiveness of fresh leaf NIRS models in the application of nutrient decision support tools.

\subsection{Nutrient Calibration}

Figure. 3 shows that the validation $R^{2}$ values were generally lower and more widely distributed compared to their corresponding calibration $\mathrm{R}^{2}$, which stressed that reporting only calibration statistics can be over-optimistic. Thus, all results in the following sections were based on the validation dataset. Additionally, NIRS models predicted macronutrients (median $\mathrm{R}^{2}=0.85$ ) more accurately compared to micronutrients (median $\mathrm{R}^{2}=0.70$ ).

[Figure. 3] 
341

342

343

344

345

346

347

348

349

350

351

352

353

354

355

356

357

358

359

360

361

362

363

364

365

366

367

368

369

370

371

372

373

374

375

376

377

\subsection{Macronutrients}

Overall, all macronutrients were accurately predicted by NIRS, except for nitrate-N which had the lowest validation $R^{2}$ of 0.41 . The complete accuracy parameters of the NIR models in estimating macronutrients are shown in Supplementary Table 2. Leaf total $N$ had the highest validation $R^{2}$ at 0.94 followed by $\mathrm{Ca}, \mathrm{S}$, and $\mathrm{Mg}$ with validation $\mathrm{R}^{2}$ values $\geq 0.80$. Validation $R^{2}$ values for $P$ and $K$ were relatively lower compared to other macronutrients.

Despite the high prediction accuracy of total $\mathrm{N}$, nitrate- $\mathrm{N}$ was poorly predicted by NIRS with a low validation $R^{2}$ of 0.41 , and a large bias (Supplementary Table 2, Supplementary Table 3). Petiole total N, however, was better predicted compared to nitrate-N by NIRS models. The relatively lower validation accuracy of the petiole total $\mathrm{N}$ might be due to the smaller sample size $(n=115)$ used in the calibration. There is potential for the calibration to be improved further using a larger sample size with a wider and well-distributed petiole total $\mathrm{N}$ content.

\subsection{Micronutrients}

Sodium had the highest validation $\mathrm{R}^{2}(0.76)$. Micronutrients that had a higher validation $R^{2}$ value compared to the $R^{2}$ median value for micronutrients $(0.70)$ were $\mathrm{Mo}, \mathrm{Mn}, \mathrm{Na}$, Fe. Validation $\mathrm{R}^{2}$ values for $\mathrm{B}$ and $\mathrm{Cl}$ were around the median values. Zinc was the least accurately predicted micronutrient with a validation $R^{2}$ of 0.36 (NIR). Hence, NIRS cannot be used to predict $\mathrm{Zn}$ content in cotton leaves. The complete accuracy parameters of the NIRS calibration in predicting different micronutrients are shown in Supplementary Table 3.

\subsection{Leaf Sample Preparation}

The following sections show the potential application of the NIR spectrometer in the field by comparing the accuracy of the models developed from cotton leaves at different conditions.

\subsubsection{Dried and Ground vs. Fresh and Removed samples}

The paired t-test output comparing the prediction accuracy between models built using dried and ground leaf samples and fresh and removed leaf samples in predicting macroand micronutrients are shown in Table 2. Based on the validation RMSE, macronutrients that were predicted with equal accuracies by both leaf sample conditions were $P, K, M g$, 
378

379

380

381

382

383

384

385

386

387

388

389

390

391

392

393

394

395

396

397

398

399

400

401

402

403

404

405

406

407

408

409

410

411

412

413

414

415

and nitrate-N. Prediction using models derived from dried and ground leaves were significantly more accurate $(p<0.01)$ for total $\mathrm{N}, \mathrm{Ca}$, and $\mathrm{S}$ compared to fresh and removed leaf models. Most micronutrients were significantly predicted more accurately using dried and ground leaf models. There were only two micronutrients $(\mathrm{Cl}$ and $\mathrm{Mn})$ that were predicted with a similar accuracy by models derived from both leaf conditions. Boron was the only micronutrient that was predicted more accurately by fresh and removed models.

\section{[Table 2]}

\subsubsection{Fresh and Removed vs. Fresh and Intact Samples}

Table 3 shows the paired t-test comparing the prediction accuracy of the models derived from fresh and removed leaves and fresh and intact leaves in predicting macro-and micronutrients. Most macronutrients were predicted with similar accuracies by both the fresh and removed and fresh and intact leaf models $(p<0.01)$. The majority of micronutrients were predicted with similar accuracies by fresh and removed and fresh and intact leaf models, except for $\mathrm{Cu}$ (better under fresh and removed leaves) and $\mathrm{Mn}$ and $\mathrm{Na}$ (better under fresh and intact).

\section{[Table 3]}

\subsection{Effectiveness of leaf NIRS models on a nutrient decision system}

This section compared the analysis results of NutriLOGIC, a decision support system used in the Australian cotton industry for fertiliser recommendations (when supplied with laboratory analysis measurements) vs. NIRS prediction. Based on the lab-measured leaf macronutrients (N, P, K, S, Ca, Mg), NutriLOGIC categorised $45.3 \%, 33.3 \%$, and $21.3 \%$ of the sample macronutrient measurements as high, low, and normal, respectively. Whereas, using values predicted by fresh leaf models (this study), NutiLOGIC categorised $43.3 \%, 29.3 \%$, and $27.3 \%$ of the sample macronutrient measurements as high, low, and normal respectively (supplementary Table 6). The overall error rate of nutrient status classification is $12.7 \%$.

For micronutrients ( $\mathrm{Na}, \mathrm{Zn}, \mathrm{Fe}, \mathrm{Cu}, \mathrm{Mn}, \mathrm{B}$ ), NutriLOGIC categorised $32.7 \%, 42.0 \%$, and $25.3 \%$ of the lab-based micronutrient measurements as high, low, and normal respectively. Using values predicted with fresh leaf models, NutiLOGIC provided a rating 
416 of $31.3 \%, 44.7 \%$, and $24.0 \%$ of the sample micronutrient measurement as high, low, and 417 normal, respectively (supplementary Table 6). The overall error rate of nutrient status 418 classification is $13.3 \%$.

Overall, using NIRS prediction of fresh leaves as compared to laboratory analysis resulted in a nutrient status classification error rate of $12.7 \%$ for macronutrients and $13.3 \%$ for micronutrients.

423

424

425

\section{Discussion}

\subsection{Macronutrients vs. Micronutrients}

Generally, macronutrients were predicted at higher accuracies compared to micronutrients via NIRS. These results agree with past studies (Petisco et al., 2005; Huang et al., 2008; Petisco et al., 2008; Liao et al., 2012), which found that macronutrients on leaves such as $\mathrm{N}, \mathrm{P}, \mathrm{K}, \mathrm{Ca}$ and $\mathrm{Mg}$ are generally predicted better compared to micronutrients such as $\mathrm{Fe}, \mathrm{Zn}, \mathrm{Mn}$, and $\mathrm{B}$. Despite this, the prediction accuracies for estimating micronutrients in this study were better compared to other studies that found $\mathrm{R}^{2}$ of $0.00-0.69$ for most micronutrients except for Zn (Petisco et al., 2008; Liao et al., 2012; van Maarschalkerweerd et al., 2013).

Macronutrients were estimated with high accuracy by NIRS in this study because most macronutrients (i.e., N, P, and S) exist dominantly in organic form (Droux, 2004; Marschner, 2011). Nutrients in organic form can be directly measured by NIRS, as organic compounds contain chemical bonds such as $\mathrm{C}-\mathrm{H}, \mathrm{N}-\mathrm{H}, \mathrm{S}-\mathrm{H}, \mathrm{C}-\mathrm{C}$, and $\mathrm{C}=\mathrm{C}$ that have a unique signature in the NIR range (Richardson et al., 2004). For example, wavelengths used by the model for predicting total $\mathrm{N}$ (Figure. 4, Figure. 5) corresponded to protein and chlorophyll compounds, which is also reported by other studies (Al-Abbas et al., 1974; Johnson, 2001; Min et al., 2006; Shao and He, 2013). The distribution of important wavelengths used by the Cubist model in predicting leaf total $\mathrm{N}$ is shown in Figure. 5.

\section{[Figure. 4.]}

The importance of the reflectance spectra at wavelength $2225 \mathrm{~nm}$ (Figure. 4) indicated the relevance of protein in determining the $\mathrm{N}$ content of leaves, as protein corresponds to wavelengths 2054 and $2712 \mathrm{~nm}$ due to the $\mathrm{C}-\mathrm{H}$ and N-H bonds (Kokaly, 2001; Bojović and Marković, 2009). These wavelength bands are also correlated to the $\mathrm{C}-\mathrm{H}$ bonds in the phytol tails of chlorophyll (Sims and Gamon, 2002). Similar results were reported by 
454 Min et al. (2006) who found a strong relationship between the $\mathrm{N}$ content of Chinese

455

456

457

458

459

460

461

462

463

464

465

466

467

468

469

470

471

472

473

474

475

476

477

478

479

480

481

482

483

484

485

486

487

488

489

490

491

492

cabbage with reflectance at 2229 and $2283 \mathrm{~nm}$.

Despite numerous studies such as Farabee (2003) and Sims and Gamon (2002) showing that chlorophyll, which is more prominent in the visible spectrum due to its $\mathrm{C}-\mathrm{C}$ and $\mathrm{C}=\mathrm{C}$ bonds in the porphyrin ring provides a strong indication of the $\mathrm{N}$ content in leave tissues, NIRS was able to accurately total $\mathrm{N}$ content. This shows that protein is a stronger indicator compared to chlorophyll in indicating the total $\mathrm{N}$ content of leaves.

Another successful example of how macronutrients are predicted by NIRS is the accurate prediction of $\mathrm{P}$ content, which was expected because, similar to $\mathrm{N}, \mathrm{P}$ exists mostly in organic form in plants in the form of phytates (50-70\%), nucleic acids, phosphoproteins, phospholipids (20-30\%), and the remaining existing as inorganic P (Chen et al., 2002; Petisco et al., 2005). The important wavelengths included $2390-2400 \mathrm{~nm}$ in the NIR calibration. These wavelength bands were comparable to the findings of De Boever et al. (1994) who found a high correlation between the $2200-2400 \mathrm{~nm}$ and the total $P$ and phytate $\mathrm{P}$ content in vegetables and a slightly lower correlation at the $2048 \mathrm{~nm}$ wavelength. Similarly, Petisco et al. (2005) found that important wavelengths used in predicting $\mathrm{P}$ are close to $2330 \mathrm{~nm}$ which are correlated to phospholipids.

Conversely, most micronutrients and several macronutrients such as $\mathrm{Mg}$ and $\mathrm{Ca}$ exist in inorganic forms that are associated with organic compounds, largely as enzyme cofactors, whereas $\mathrm{K}$ is the only nutrient that is not a constituent of any organic compounds (Marschner, 2011). In this study, these macronutrients and micronutrients were well predicted by NIRS. The inability of NIRS to directly detect inorganic compounds suggests alternative mechanisms:

(1) via the association of nutrients with the functional groups of organic compounds or directly to the organic matrix (Huang et al., 2008; Yarce and Rojas, 2012), and

(2) indirectly by measuring organic compounds that can directly be detected by NIRS that are correlated with the nutrients (Sims and Gamon, 2002).

For example, $\mathrm{K}$ is an essential macronutrient due to its importance in managing more than 50 enzymes essential in maintaining the functioning of plants (Ciavarella et al., 1998; Galvez-Sola et al., 2015). Different from other macronutrients, $\mathrm{K}$ is not incorporated into the chemical structure of plant tissues and it is most influential in $\mathrm{K}^{+}$ionic form or its inorganic form (Ciavarella et al., 1998; Prajapati and Modi, 2012) which is not readily detected by NIRS. The wavelength regions used in the NIRS model for $\mathrm{K}$ corresponded to wavelengths associated with sucrose between $1800-2100 \mathrm{~nm}$ (Giangiacomo, 2006). This also coincided with the regions associated with other carbohydrates (Rébufa et al., 2018).

PeerJ reviewing PDF | (2020:08:52088:2:0:NEW 4 Jan 2021) 
493

494

495

496

497

498

499

500

501

502

503

504

505

506

507

508

509

510

511

512

513

514

515

516

517

518

519

520

521

522

523

524

525

526

527

528

529

530

531

The association of $\mathrm{K}$ with carbohydrates and organic acids and its correlation with the near infrared spectra can be explained by the two alternate mechanisms mentioned above. First, $\mathrm{K}$ is influential in photosynthesis and translocation of assimilates such as sucrose, cellulose, and starch; hence, the abundance of these assimilates and organic acids (e.g., malic acids) which can be directly measured by NIRS, can be correlated indirectly to the abundance of $\mathrm{K}$ in the plants (Ciavarella et al., 1998). Secondly, $\mathrm{K}$ also forms cation-carbohydrate complexes that are detectable by NIRS (Cadet and Offmann, 1996). These two mechanisms show that there is a possibility for nutrients that mostly exist in inorganic form in plant tissues to be detected via NIRS.

Another factor that is responsible for the higher NIRS model prediction accuracies of macronutrients is their higher concentration (Clark et al., 1987; Liao et al., 2012). In general, the result also agrees with Liao et al. (2012) which stated that reliable NIR calibration could only be achieved with nutrients of concentrations above $100 \mathrm{mg} / \mathrm{kg}$ as shown by the poor validation $\mathrm{R}^{2}$ for $\mathrm{Zn}(0.36)$ for which its concentration ranged from 8.14$64.62 \mathrm{mg} / \mathrm{kg}$. Thus, the comparable validation accuracies of several micronutrients such as $\mathrm{Fe}, \mathrm{Mn}, \mathrm{Na}$, and $\mathrm{Mo}$ to macronutrients such as $\mathrm{K}$ and $\mathrm{P}$ can be explained by their concentrations that are generally higher than $100 \mathrm{mg} / \mathrm{kg}$ in terms of abundance (Table 2). Despite this, Cu (<15 mg/kg) which had a lower concentration compared to $\mathrm{Zn}$ had a reasonable validation $\mathrm{R}^{2}$ of 0.65 . This result contradicts the findings of de Aldana et al. (1995) that found Vis-NIR was unsuccessful in predicting $\mathrm{Cu}$ in different plants.

This successful prediction of $\mathrm{Cu}$ can be related to its positive correlation to the leaf total $\mathrm{N}$ (linear correlation coefficient, $r=0.70$ ), whereas $\mathrm{Zn}$ content was not correlated to other well-estimated nutrients. The correlation between $\mathrm{Cu}$ and total $\mathrm{N}$ explains the validation $\mathrm{R}^{2}$ of $\mathrm{Cu}(0.65)$, accounting for approximately $70 \%$ of the validation $\mathrm{R}^{2}$ of the total $\mathrm{N}$ calibrations (0.94). To infer the mechanism behind the prediction of $\mathrm{Cu}$ by NIRS, Figure. 5 shows the important wavelengths used in the NIRS model to estimate Cu and total N.

\section{[Figure. 5]}

The wavelength bands used in the NIRS calibrations for estimating Cu coincided with the wavelength bands used to estimate leaf total N (Figure. 5). Marschner (2011) stated that $98 \%$ of $\mathrm{Cu}$ in plants occur in complex forms with proteins due to its affinity to peptide. Additionally, $50 \%$ of $\mathrm{Cu}$ in plants exist in the chloroplast taking part in the photosynthesis process (Marschner, 2011). These two factors provide comprehensive support to the high correlation found between the $\mathrm{Cu}$ content and leaf total $\mathrm{N}$ content. 
532 In summary, NIRS were able to accurately measure macronutrients such as $\mathrm{N}, \mathrm{P}$, and $\mathrm{S}$ 533 directly, as these nutrients are major constituents of NIRS sensitive-organic compounds 534 such as proteins and nucleic acids. Moreover, NIRS can also accurately predict 535 macronutrients and micronutrients that are dominantly present in inorganic form through 536 their association with NIRS sensitive-organic compounds, or as organic complexes, and 537 indirectly through correlated organic compounds. Despite the lower concentrations of 538 micronutrients such as $\mathrm{Cu}$, their association with organic compounds (i.e., proteins) 539 enables it to be measured by NIRS.

540

541

Nitrate- $\mathrm{N}$ behaves closer to micronutrients in that it exists in a relatively low concentration

542 compared to organic $\mathrm{N}$, on average $3 \%$ of total $\mathrm{N}$ in this study, and it is categorised as an

543 inorganic compound. Despite the higher concentration of nitrate- $\mathrm{N}$ compared to most

544 micronutrients, nitrate- $\mathrm{N}$ was poorly predicted by the NIRS model. The inability to predict nitrate-N can be due to the mobility of nitrate- $\mathrm{N}$ in plant tissues (Marschner, 2011). Nitrate$\mathrm{N}$ is accumulated in the vacuole $(5-75 \mu \mathrm{M})$ of plant cells with a small portion existing in the cytosol $(1-5 \mu \mathrm{M})$; however, nitrate-N is readily transported throughout the plant and it is quickly depleted in certain conditions (Marschner, 2011).

549

\subsection{Fresh vs. Dried samples}

551

552

553

554

555

556

557

558

559

560

561

562

563

564

565

566

567

568

569

570

571

Expectedly, models using dried and ground leaf gave a more accurate estimation of both macro- and micronutrient content of cotton leaves compared to models calibrated using fresh leaf samples. This result coincided with Rotbart et al. (2013) who found that dried and ground olive leaves provide a better prediction accuracy in predicting leaf nutrient content compared to fresh leaf derived models. The major advantage of dried and ground leaf samples is the low moisture content in samples. Water molecules have a strong effect on NIR reflectance spectra, especially at wavelengths of 1400 and $1950 \mathrm{~nm}$ (Figure. 6) (Rambla et al., 1997; Jie et al., 2014). This water influence can be attributed to the vibration of the O-H bond in water molecules (Ludwig and Khanna, 2001).

\section{[Figure. 6]}

Moreover, dried and ground samples are more homogenous and provide a more complete representation of the sample's chemical composition. Despite the advantages of using standardised samples, half of the macronutrients assessed (i.e., P, K, and Mg) were predicted equally well by fresh leaf models. Macronutrients that were significantly more accurately predicted by dried and ground leaf models (i.e., Total N, Ca, and S) had validation RMSEs that were still acceptable when fresh samples were used. Wavelengths used by dried and ground leaf and fresh leaf models in estimating leaf nutrient contents were quite different with some overlap (Figure. 7). Fresh leaf models used a wider range of wavelengths, whereas dried and ground leaf models used a narrower range (Figure. 
572 7). This could be a method for NIRS to compensate for the reduced information in the 573 fresh leaf spectrum from moisture influence.

574

575

576

577

\section{[Figure. 7]}

578

579

580

581

582

583

584

585

586

587

588

589

590

591

592

593

594

595

596

597

598

599

600

601

602

603

604

605

606

607

608

609

610

611

Conversely, micronutrients were not well predicted by fresh leaf models, except for $\mathrm{Mn}$ and $\mathrm{Cl}$. The lower prediction accuracy may be attributed to the lower signal of micronutrients, which may be overwhelmed by the water influence in fresh leaf samples. However, the validation RMSEs of the fresh leaf calibration were still acceptable compared to the validation RMSEs of the dried and ground validation RMSEs. On average, using models of fresh and removed leaves instead of dried and ground leaves reduced the prediction accuracy by $19 \%$ for macronutrients and $11 \%$ for micronutrients. This accuracy loss equates to a $0.04 \%$ lower accuracy for total $\mathrm{N}$, and a loss of $7 \mathrm{mg} / \mathrm{kg}$ accuracy for $\mathrm{Fe}$, which can be considered acceptable for agronomic purposes. Hence, NIRS has a large potential to be used for in-field application of cotton plant macronutrient analysis. For micronutrients that have low concentration, NIRS can be used as screening tests to indicate deficiencies.

From the two methods for obtaining fresh cotton leaf NIR scan, fresh and intact and fresh and removed leaves were quite similar in accuracy based on the validation RMSE. Several nutrients were better predicted under fresh and intact leaf conditions. However, the overall difference is negligible. The only difference between the two fresh leaves was the moisture content, as removed fresh leaves had, on average, $7 \%$ less moisture compared to intact leaves. Moisture content decreased with time as leaf samples were removed from the plant.

This study on fresh and intact leaves was conducted on a glasshouse with a controlled environment. In terms of practicality, acquiring NIR spectra data from fresh and removed leaves is the preferable option, as sample conditions are more controlled, and it avoids extreme terrains or weather conditions. Temperature variation can be an issue for the application of NIRS in-field because it can also affect the NIR spectrum (Roger et al., 2003; Nicolai et al., 2007). Temperature can alter the chemical composition of plant tissues, as it affects the abundance of organic compounds (Roger et al., 2003; Nicolai et al., 2007). The application of NIRS at different sampling temperatures or moisture conditions can result in inconsistent readings (Roger et al., 2003; Minasny et al., 2011). Thus, conducting measurements in a more controlled temperature would be more beneficial.

In the Australian cotton industry, NutriLOGIC is an important decision support tool used by cotton farmers. Currently, due to the delay in acquiring nutrient status information, the 
612 use of NutriLOGIC is still inefficient. From the comparisons between lab-measured 613 nutrient status and NIRS predicted nutrients status (using the fresh leaf model), it was 614 found that the error of nutrient classification was $12.7 \%$ for macronutrient and $13.3 \%$ for 615 micronutrient. The small difference in classification error between macronutrients and 616 micronutrients despite the lower accuracy of micronutrient NIRS models shows that the 617 accuracy of micronutrient NIRS models are acceptable for the purpose of NutriLOGIC. 618 Moreover, this error rate can be compensated by conducting scans on more samples. As 619 NIRS readings are rapid, multiple scans can be done quickly to further reduce error in 620 sampling and readings. This demonstrates that NIRS can accurately obtain plant nutrient 621 status information in real-time, which will improve the efficiency and effectiveness of a 622 decision support system.

623

624

625

\section{Conclusions}

626

627

In conclusion, NIRS can be a tool that can provide rapid and real-time cotton plant nutrient

628 analysis. All macronutrients, i.e., total $\mathrm{N}, \mathrm{P}, \mathrm{K}, \mathrm{Ca}, \mathrm{Mg}$, and $\mathrm{S}$ were estimated with high

629 accuracies, and most micronutrients, i.e., $\mathrm{Fe}, \mathrm{Mn}, \mathrm{Cu}, \mathrm{Mo}, \mathrm{B}, \mathrm{Cl}$, and $\mathrm{Na}$ were estimated

630

631 with relatively high accuracy by NIRS. Macronutrients were generally predicted with higher accuracy by NIRS due to their higher concentration, and important macronutrients

632 such as total N, P, and S exist in NIRS sensitive-organic compounds, whereas $\mathrm{Ca}, \mathrm{Mg}$,

633 $\mathrm{K}$, and micronutrients that exist dominantly in inorganic form were measured through their

634 association with organic compounds or indirectly through correlation with organic

635

636

637 compounds. (Johnson et al., 2020)

638

The small reduction in accuracy from models calibrated using standard dried and ground leaves to the models calibrated using fresh and removed leaves shows that there is a

639 strong potential for NIRS to be used in-field. Moreover, nutrients levels predicted using

640 fresh leaf models are accurate enough to be applied to decision support tools such as

641

642 NutriLOGIC. This enables rapid nutrient analysis that can prompt effective nutrient

643 management. Further research should directly link NIRS and nutrient management by

644 developing models that use the estimated plant nutrient status information to directly

645

646 calculate a fertiliser prescription rate based on plant's growth stage.

647

648 The authors thank Ms. Kellie Gordon and Ms. Phebe Samrani for their technical 649 assistance. BM acknowledges the contribution from Sydney Institute of Agriculture's

650

651

\section{Acknowledgements} Nitrogen use efficiency project. This research received financial support from CSIRO Agriculture \& Food Strategic Investment project (SIP) funds. 
652

653

654

655

656

657

658

659

660

661

662

663

664

665

666

667

668

669

670

671

672

673

674

675

676

677

678

679

680

681

682

683

684

685

686

687

688

689

690

691

692

693

694

695

696

697

698

699

700

\section{References}

Al-Abbas, A., Barr, R., Hall, J., Crane, F., Baumgardner, M., 1974. Spectra of Normal and Nutrient-Deficient Maize Leaves 1. Agronomy Journal 66, 16-20.

Ali, S., Khan, A.R., Mairaj, G., Arif, M., Fida, M., Bibi, S., 2008. Assessment of different crop nutrient management practices for yield improvement. Australian Journal of Crop Science 2, 150157.

Au, J., Youngentob, K.N., Foley, W.J., Moore, B.D., Fearn, T., 2020. Sample selection, calibration and validation of models developed from a large dataset of near infrared spectra of tree leaves. Journal of Near Infrared Spectroscopy 28, 186-203.

Beegle, D.B., Carton, O., Bailey, J., 2000. Nutrient management planning: justification, theory, practice. Journal of Environmental Quality 29, 72-79.

Bojović, B., Marković, A., 2009. Correlation between nitrogen and chlorophyll content in wheat (Triticum aestivum L.). Kragujevac Journal of Science 31, 69-74.

Cadet, F., Offmann, B., 1996. Evidence for Potassium-Sucrose Interaction in Biological MidInfrared Spectra by Multidimensional Analysis. Spectroscopy Letters 29, 1353-1365.

Chen, M., Glaz, B., Gilbert, R.A., Daroub, S.H., Barton, F.E., Wan, Y., 2002. Near-infrared reflectance spectroscopy analysis of phosphorus in sugarcane leaves. Agronomy Journal 94, 1324-1331.

Ciavarella, S., Batten, G.D., Blakeney, A.B., 1998. Measuring potassium in plant tissues using near infrared spectroscopy. Journal of Near Infrared Spectroscopy 6, A63-A66.

Clark, D., Mayland, H., Lamb, R., 1987. Mineral Analysis of Forages with near Infrared Reflectance Spectroscopy 1. Agronomy Journal 79, 485-490.

Cotton Australia, 2018. ECONOMICS. https://cottonaustralia.com.au/australian-cotton/ economics (accessed 22 September 2019).

Cotton Research and Development Corporation (CRDC), CottonInfo, 2019. Australian Cotton Production Manual. https://www.cottoninfo.com.au/sites/default/files/documents/ACPM\% 202019\%20final.pdf (accessed 10 October 2019).

Cuq, S., Lemetter, V., Kleiber, D., Levasseur-Garcia, C., 2020. Assessing macro-element content in vine leaves and grape berries of vitis vinifera by using near-infrared spectroscopy and chemometrics. International Journal of Environmental Analytical Chemistry 100, 1179-1195.

de Aldana, B.V., Criado, B.G., Ciudad, A.G., Corona, M.P., 1995. Estimation of mineral content in natural grasslands by near infrared reflectance spectroscopy. Communications in Soil Science and Plant Analysis 26, 1383-1396. 
701

702

703

704

705

706

707

708

709

710

711

712

713

714

715

716

717

718

719

720

721

722

723

724

725

726

727

728

729

730

731

732

733

734

735

736

737

738

739

740

741

742

743

744

745

746

747

748

749

750

De Boever, J., Eeckhout, W., Boucque, C.V.J.N.w.j.o.I.s., 1994. The possibilities of near infrared reflection spectroscopy to predict total-phosphorus, phytate-phosphorus and phytase activity in vegetable feedstuffs. NJAS wageningen journal of life sciences 42, 357-369.

Dedeoglu, M., 2020. Estimation of critical nitrogen contents in peach orchards using visible-near infrared spectral mixture analysis. Journal of Near Infrared Spectroscopy 28, 315-327.

Deutscher, S., Bange, M., Rochester, I., 2001. Testing NutriLOGIC, a decision aid for nitrogen fertiliser management in cotton. Proceedings of the 10th Australian Agronomy Conference, Hobart, TAS, Australia.

Dobermann, A., 2007. Nutrient use efficiency-measurement and management. Fertilizer best management practices 1. IFA.

Droux, M., 2004. Sulfur assimilation and the role of sulfur in plant metabolism: a survey. Photosynthesis Research 79, 331-348.

Fageria, N., Baligar, V., 2005. Enhancing nitrogen use efficiency in crop plants. Advances in agronomy $88,97-185$.

Farabee, M., 2003. Photosynthesis. Avondale, Ariz.: Estrella Mountain Community College.

Galvez-Sola, L., García-Sánchez, F., Pérez-Pérez, J.G., Gimeno, V., Navarro, J.M., Moral, R., Martínez-Nicolás, J.J., Nieves, M., 2015. Rapid estimation of nutritional elements on citrus leaves by near infrared reflectance spectroscopy. Frontiers in Plant Science 6, 571.

García-Martínez, S., Gálvez-Sola, L.N., Alonso, A., Agulló, E., Rubio, F., Ruiz, J.J., Moral, R., 2012. Quality assessment of tomato landraces and virus-resistant breeding lines: quick estimation by near infrared reflectance spectroscopy. Journal of the Science of Food and Agriculture 92, 1178-1185.

Giangiacomo, R., 2006. Study of water-sugar interactions at increasing sugar concentration by NIR spectroscopy. Food Chemistry 96, 371-379.

Grundon, N.J., 2006. Nutrient deficiency and toxicity symptoms. Encyclopedia of soil science, 2nd edn. Taylor \& Francis, pp. 1144-1146.

Hallikeri, S., Halemani, H., Patil, V., Palled, Y., Patil, B., Katageri, I., 2010. Effect of nitrogen levels, split application of nitrogen and detopping on seed cotton yield and fibre quality in Btcotton. Karnataka Journal of Agriculture Sciences 23, 418-422.

Houba, V.J.G., Lexmond, T.M., Novozamsky, I., Van der Lee, J.J., 1996. State of the art and future developments in soil analysis for bioavailability assessment. Science of the Total Environment, 178, 21-28.

Huang, G., Han, L., Yang, Z., Wang, X., 2008. Evaluation of the nutrient metal content in Chinese animal manure compost using near infrared spectroscopy (NIRS). Bioresource Technology 99, 8164-8169.

Peer) reviewing PDF | (2020:08:52088:2:0:NEW 4 Jan 2021) 
751

752

753

754

755

756

757

758

759

760

761

762

763

764

765

766

767

768

769

770

771

772

773

774

775

776

777

778

779

780

781

782

783

784

785

786

787

788

789

790

791

792

793

794

795

796

797

Jie, W., Hua-bing, Z., Chang-wei, S., Cai-xia, D., Yang-chun, X., 2014. Determination of nitrogen concentration in fresh pear leaves by visible/near-infrared reflectance spectroscopy. Agronomy Journal 106, 1867-1872.

Johnson, L.F., 2001. Nitrogen influence on fresh-leaf NIR spectra. Remote Sensing of Environment 78, 314-320.

Kokaly, R.F., 2001. Investigating a physical basis for spectroscopic estimates of leaf nitrogen concentration. Remote Sensing of Environment 75, 153-161.

Kuhn, M., Johnson, K., 2013. Regression trees and rule-based models. Applied predictive modeling. Springer, pp. 173-220.

Liao, H., Wu, J., Chen, W., Guo, W., Shi, C., 2012. Rapid diagnosis of nutrient elements in fingered citron leaf using near infrared reflectance spectroscopy. Journal of Plant Nutrition 35, 1725-1734.

Ludwig, B., Khanna, P., 2001. Use of near infrared spectroscopy to determine inorganic and organic carbon fractions in soil and litter. Assessment Methods for Soil Carbon, Lewis Publishers, pp. 361-370.

Marschner, H., 2011. Marschner's mineral nutrition of higher plants. Academic press.

Martínez-Valdivieso, D., Font, R., Río-Celestino, D., 2019. Prediction of Agro-Morphological and Nutritional Traits in Ethiopian Mustard Leaves (Brassica Carinata A. Braun) by Visible-NearInfrared Spectroscopy. Foods 8, 6.

McQuaker, N., Brown, D., Kluckner, P., 1979. AOAC official methods of analysis 15. Analytical Chemistry 51, 1082.

Miley, W.N., Maples, R.L., Keisling, T.C., 1990. Use of Soil Nitrate Tests for Cotton Nitrogen Recommendations-An Extension Viewpoint. Nitrogen nutrition of cotton: Practical issues (eds W. Miley and D. Oosterhuis), ASA-CSSA-SSSA, pp. 65-76.

Min, M., Lee, W.S., Kim, Y.H., Bucklin, R.A., 2006. Nondestructive detection of nitrogen in Chinese cabbage leaves using VIS-NIR spectroscopy. HortScience 41, 162-166.

Minasny, B., McBratney, A.B., Bellon-Maurel, V., Roger, J.-M., Gobrecht, A., Ferrand, L., Joalland, S., 2011. Removing the effect of soil moisture from NIR diffuse reflectance spectra for the prediction of soil organic carbon. Geoderma 167, 118-124.

Ng, W., Minasny, B., Montazerolghaem, M., Padarian, J., Ferguson, R., Bailey, S., McBratney, A.B., 2019. Convolutional neural network for simultaneous prediction of several soil properties using visible/near-infrared, mid-infrared, and their combined spectra. Geoderma 352, .251-267.

Nicolai, B.M., Beullens, K., Bobelyn, E., Peirs, A., Saeys, W., Theron, K.I., Lammertyn, J., 2007. Nondestructive measurement of fruit and vegetable quality by means of NIR spectroscopy: A review. Postharvest biology and technology 46, 99-118.

PeerJ reviewing PDF | (2020:08:52088:2:0:NEW 4 Jan 2021) 
798

799

800

801

802

803

804

805

806

807

808

809

810

811

812

813

814

815

816

817

818

819

820

821

822

823

824

825

826

827

828

829

830

831

832

833

834

835

836

837

838

839

840

841

842

843

844

845

846

847

848
Peng, Y., Xiong, X., Adhikari, K., Knadel, M., Grunwald, S. Greve, M.H., 2015. Modeling soil organic carbon at regional scale by combining multi-spectral images with laboratory spectra. PloS one, 10, p.e0142295.

Petisco, C., García-Criado, B., De Aldana, B.V., Zabalgogeazcoa, I., Mediavilla, S.J.A., 2005. Use of near-infrared reflectance spectroscopy in predicting nitrogen, phosphorus and calcium contents in heterogeneous woody plant species. Analytical bioanalytical chemistry 382, 458-465.

Petisco, C., García-Criado, B., Vázquez de Aldana, B.R., García-Ciudad, A., Mediavilla, S., 2008. Ash and mineral contents in leaves of woody species: analysis by near-infrared reflectance spectroscopy. Communications in soil science and plant analysis 39, 905-925.

Prajapati, K., Modi, H., 2012. The importance of potassium in plant growth-a review. Indian Journal of Plant Sciences 1, 177-186.

Rambla, F., Garrigues, S., De La Guardia, M., 1997. PLS-NIR determination of total sugar, glucose, fructose and sucrose in aqueous solutions of fruit juices. Analytica Chimica Acta 344, 41-53.

Rayment, G.E., Lyons, D.J., 2012. New, comprehensive soil chemical methods book for Australasia. Communications in Soil Science and Plant Analysis 43, 412-418.

Read, J.J., Reddy, K.R., Jenkins, J.N., 2006. Yield and fiber quality of upland cotton as influenced by nitrogen and potassium nutrition. European Journal of Agronomy 24, 282-290.

Rébufa, C., Pany, I., Bombarda, I.J., 2018. NIR spectroscopy for the quality control of Moringa oleifera (Lam.) leaf powders: Prediction of minerals, protein and moisture contents. Food Chemistry 261, 311-321.

Richardson, A.D., Reeves III, J.B., Gregoire, T.G., 2004. Multivariate analyses of visible/near infrared (VIS/NIR) absorbance spectra reveal underlying spectral differences among dried, ground conifer needle samples from different growth environments. New Phytologist 161, 291301.

Rochester, I.J., 2011. Assessing internal crop nitrogen use efficiency in high-yielding irrigated cotton. Nutrient Cycling in Agroecosystems 90, 147-156.

Roger, J.-M., Chauchard, F., Bellon-Maurel, V., 2003. EPO-PLS external parameter orthogonalisation of PLS application to temperature-independent measurement of sugar content of intact fruits. Chemometrics and Intelligent Laboratory Systems 66, 191-204.

Rotbart, N., Schmilovitch, Z., Cohen, Y., Alchanatis, V., Erel, R., Ignat, T., Shenderey, C., Dag, A., Yermiyahu, U., 2013. Estimating olive leaf nitrogen concentration using visible and nearinfrared spectral reflectance. Biosystems Engineering 114, 426-434.

Samborski, S.M., Tremblay, N., Fallon, E., 2009. Strategies to make use of plant sensors-based diagnostic information for nitrogen recommendations. Agronomy Journal 101, 800-816.

Savi, A., de Aguiar, L., Tonial, L., Lafay, C., Assmann, T., de Bortolli, M., 2019. Fast and NonDestructive Determination of N, P, and K in Sorghum, Oat, and Corn Residue Using NearInfrared Spectroscopy. Journal of Agricultural Science 11, 304. 
849

850

851

852

853

854

855

856

857

858

859

860

861

862

863

864

865

866

867

868

869

870

871

872

873

874

875

876

877

878

879

880

881

882

883

884

885

886

887

888

889

890

891

892

893

894

895

Shao, Y., He, Y., 2013. Visible/Near infrared spectroscopy and chemometrics for the prediction of trace element (Fe and $\mathrm{Zn}$ ) levels in rice leaf. Sensors 13, 1872-1883.

Sims, D.A., Gamon, J.A., 2002. Relationships between leaf pigment content and spectral reflectance across a wide range of species, leaf structures and developmental stages. Remote Sensing of Environment 81, 337-354.

Stevens, A., Ramirez-Lopez, L., Stevens, M.A., Rcpp, L., 2015. Package 'prospectr'. Technical Report.

Tang, Y., Jones, E., Minasny, B., 2020. Evaluating low-cost portable near infrared sensors for rapid analysis of soils from South Eastern Australia. Geoderma Regional, 20, p.e00240

Tarpley, L., Reddy, K.R., Sassenrath-Cole, G.F., 2000. Reflectance indices with precision and accuracy in predicting cotton leaf nitrogen concentration. Crop Science 40, 1814-1819.

Ulissi, V., Antonucci, F., Benincasa, P., Farneselli, M., Tosti, G., Guiducci, M., Tei, F., Costa, C., Pallottino, F., Pari, L., 2011. Nitrogen concentration estimation in tomato leaves by VIS-NIR nondestructive spectroscopy. Sensors 11, 6411-6424.

van Maarschalkerweerd, M., Bro, R., Egebo, M., Husted, S., 2013. Diagnosing latent copper deficiency in intact barley leaves (Hordeum vulgare, L.) using near infrared spectroscopy. Journal of Agricultural and Food Chemistry 61, 10901-10910.

van Maarschalkerweerd, M., Husted, S., 2015. Recent developments in fast spectroscopy for plant mineral analysis. Frontiers in Plant Science 6, 169.

Van Noordwijk, M., Cadisch, G., 2002. Access and excess problems in plant nutrition. Progress in Plant Nutrition: Plenary Lectures of the XIV International Plant Nutrition Colloquium. Springer, pp. 25-40.

Yang, G., Tang, H., Nie, Y., Zhang, X., 2011. Responses of cotton growth, yield, and biomass to nitrogen split application ratio. European Journal of Agronomy 35, 164-170.

Yarce, C.J., Rojas, G., 2012. Near infrared spectroscopy for the analysis of macro and micro nutrients in sugarcane leaves. Zuckerindustrie-Sugar Industry 137, 707.

Zerner, M., Parker, K., 2019. Rapid Assessment of Crop Nitrogen and Stress Status-In-Field Assessment of a Hand-Held Near Infrared Tool. https://grdc.com.au/ resources-andpublications/grdc-update-papers/tab-content/grdc-update-papers/2019/02/rapid-assessment-ofcrop-nitrogen-and-stress-statusin-field-assessment-of-a-hand-held-near-infrared -tool (accessed 16 April 2019).

Zhang, L., Wang, L., Wang, J., Song, Z., Rehman, T.U., Bureetes, T., Ma, D., Chen, Z., Neeno, S., Jin, J., 2019. Leaf Scanner: A portable and low-cost multispectral corn leaf scanning device for precise phenotyping. Computers and Electronics in Agriculture 167, 105069.

Peer) reviewing PDF | (2020:08:52088:2:0:NEW 4 Jan 2021) 


\section{Figure 1}

Reflectance spectra of cotton leaves at different sample preparations.

(A) Reflectance spectra pattern of fresh and intact leaves. (B) Reflectance spectra pattern of fresh and removed leaves. (C) Reflectance spectra pattern of dried and ground leaves that were scanned using the PhoneLab ${ }^{\mathrm{TM}}$. The reflectance spectra were comparable between fresh and intact and fresh and removed cotton leaves; however, the reflectance spectra of dried and ground cotton leaves were distinctive from fresh cotton leaves. 

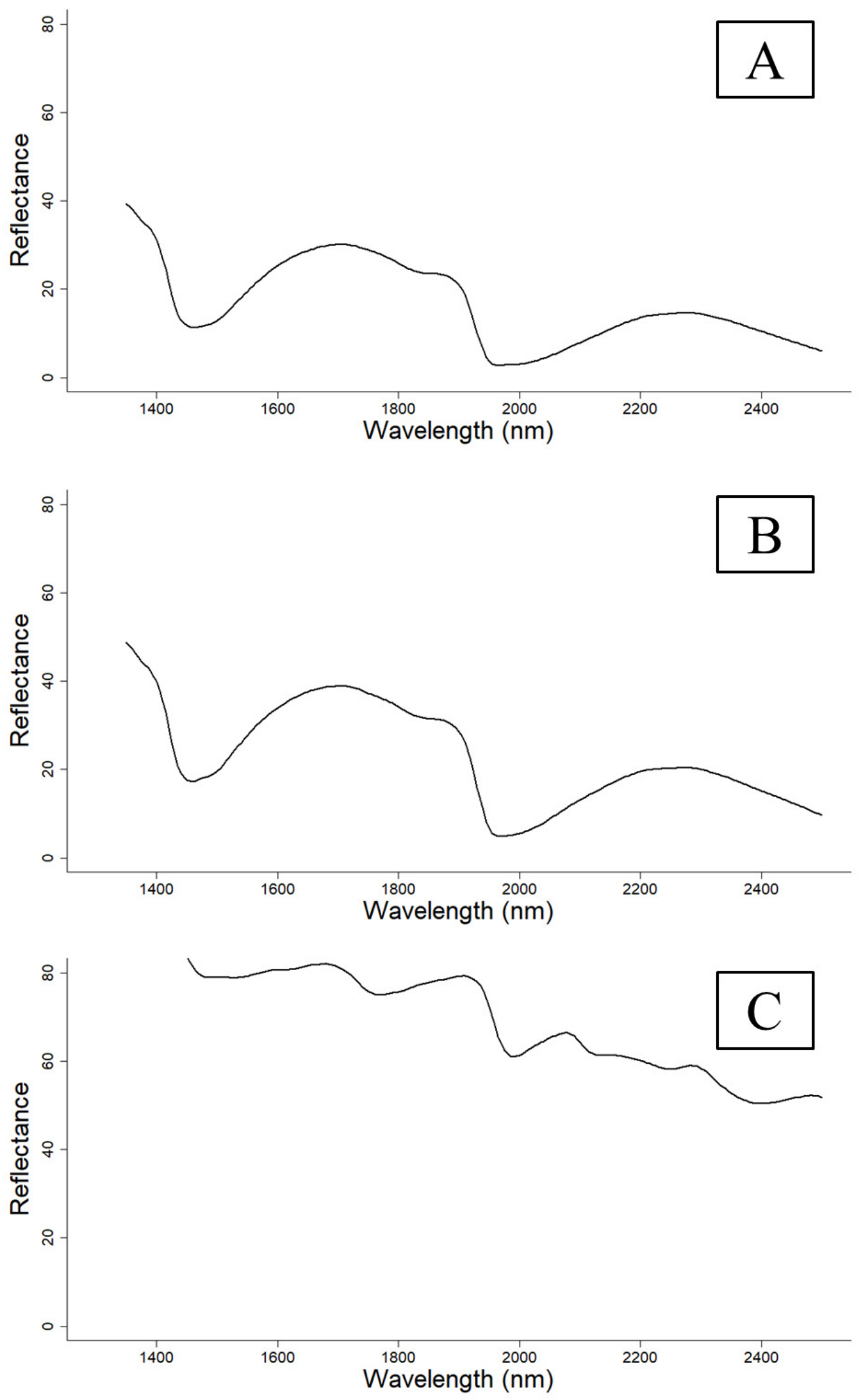


\section{Figure 2}

Picture of the near infrared spectroscopy equipment used in this study.

The system includes the handheld NIR spectrometer (PhoneLab ${ }^{T M}$ ) and the user friendly software interface that can be used on android devices.

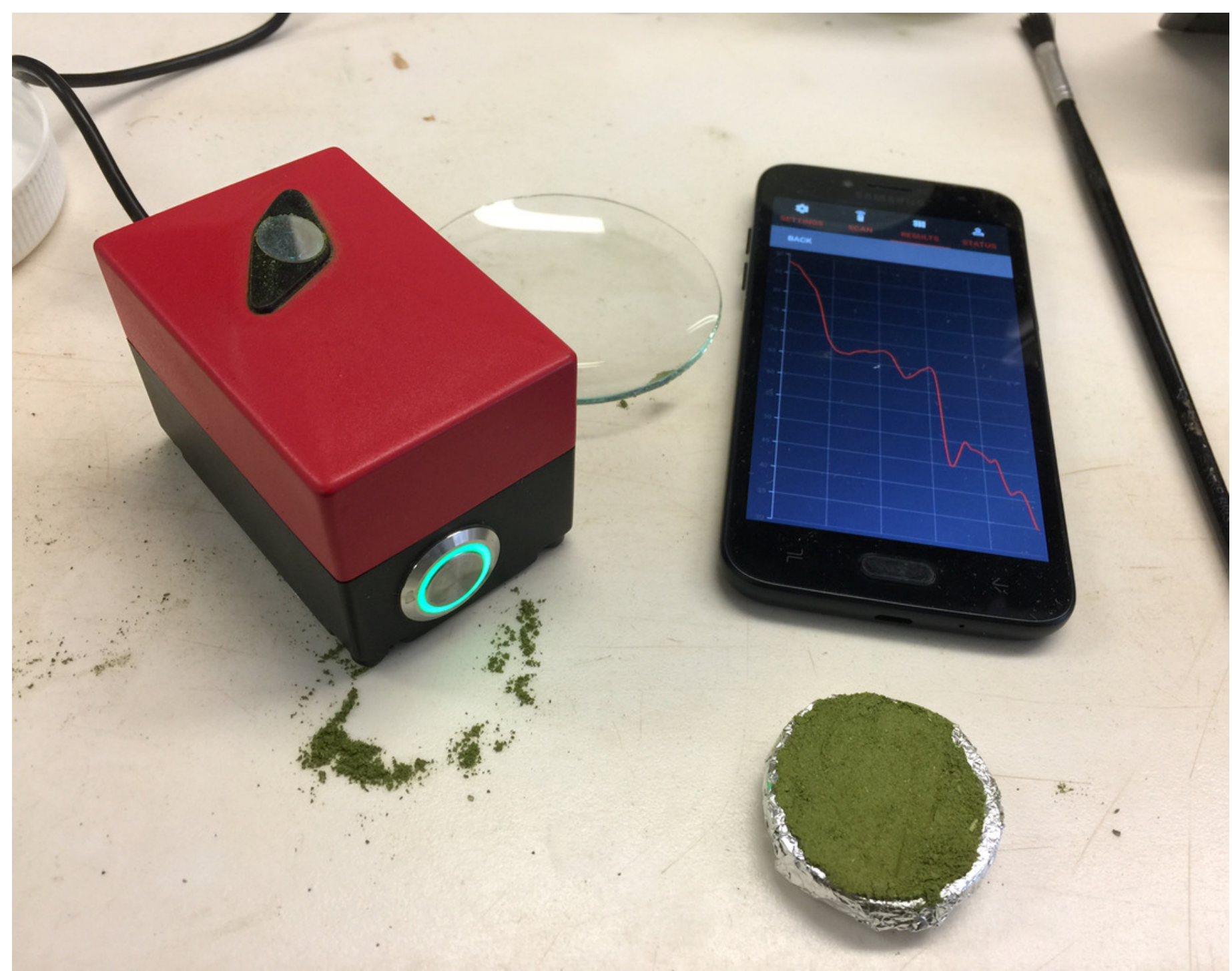


Figure 3

Boxplot comparing the statistical distribution of the calibration and validation $\mathrm{R}^{2}$ of NIRS models in predicting macro-and micronutrient content in cotton leaves.

Statistical distribution is available in supplementary Table 1.
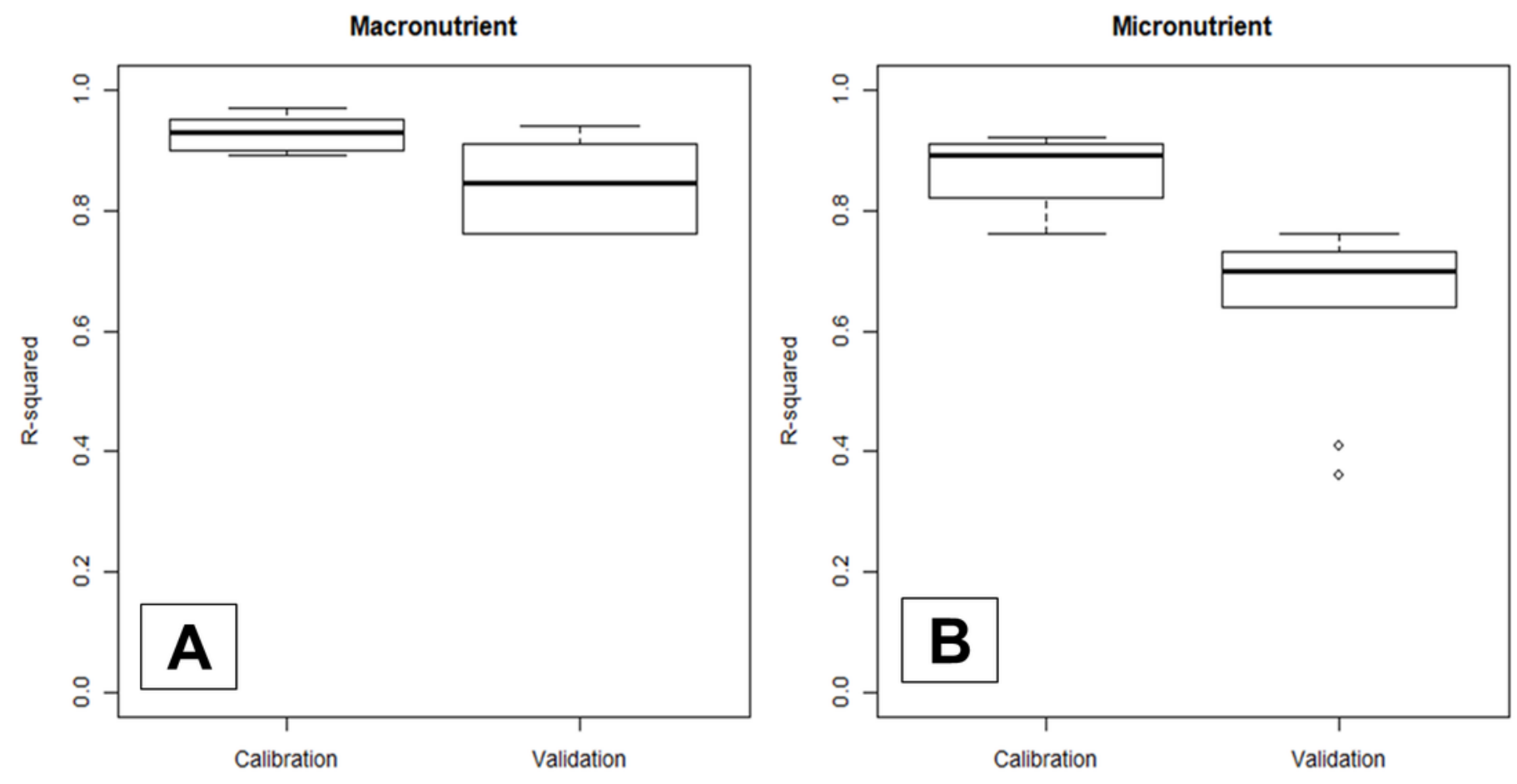
Figure 4

Important wavelengths used in the NIRS to predict total $\mathrm{N}$ content of cotton leaves.

The important wavelengths used in the NIR model are located in the $2225 \mathrm{~nm}$ and other important wavelength bands are located in region between $2200-2500 \mathrm{~nm}$. The level of importance represents the top three most important wavelengths used in the 50 iterations of the Cubist model to predict the leaf nutrients. The construction of the graph is explained in section 2.5 .

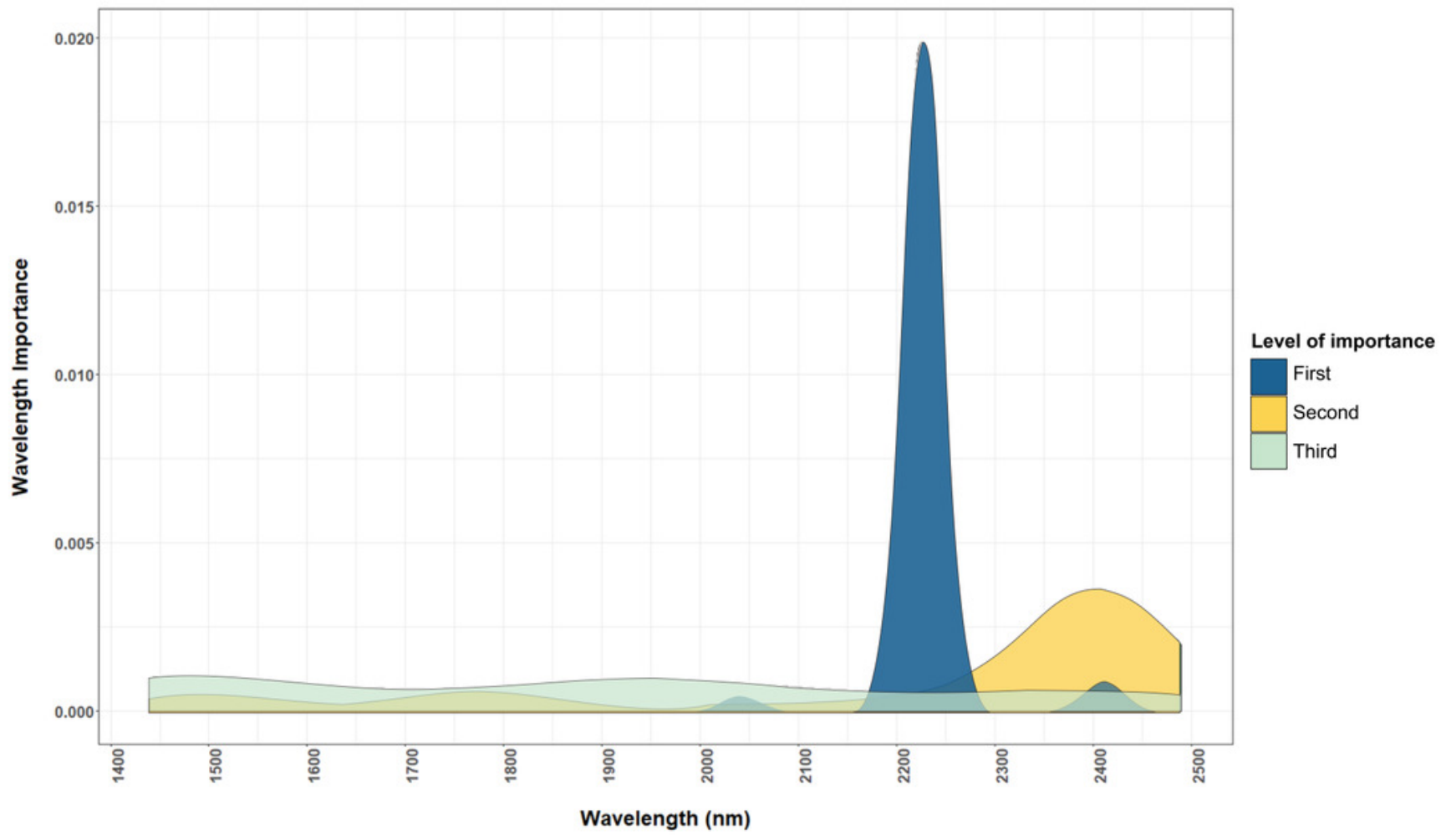




\section{Figure 5}

Comparison of important wavelenghts used by the NIRS models to predict total $\mathrm{N}$ and $\mathrm{Cu}$.
A) Important wavelength bands used in the NIRS, dried and ground leaf models to estimate the total $\mathrm{N}$ content of cotton leaf. (B) Important wavelength bands used in the NIRS, dried and ground leaf models to estimate the total $\mathrm{Cu}$ content of cotton leaf. The main wavelength bands used for estimating total $\mathrm{N}$ and $\mathrm{Cu}$ are located in the NIR range $(2200-2400 \mathrm{~nm})$. The level of importance shows the top three most important wavelengths used in the 50 iterations of the Cubist model to predict the leaf nutrients. The construction of the graph is explained in section 2.5 . 


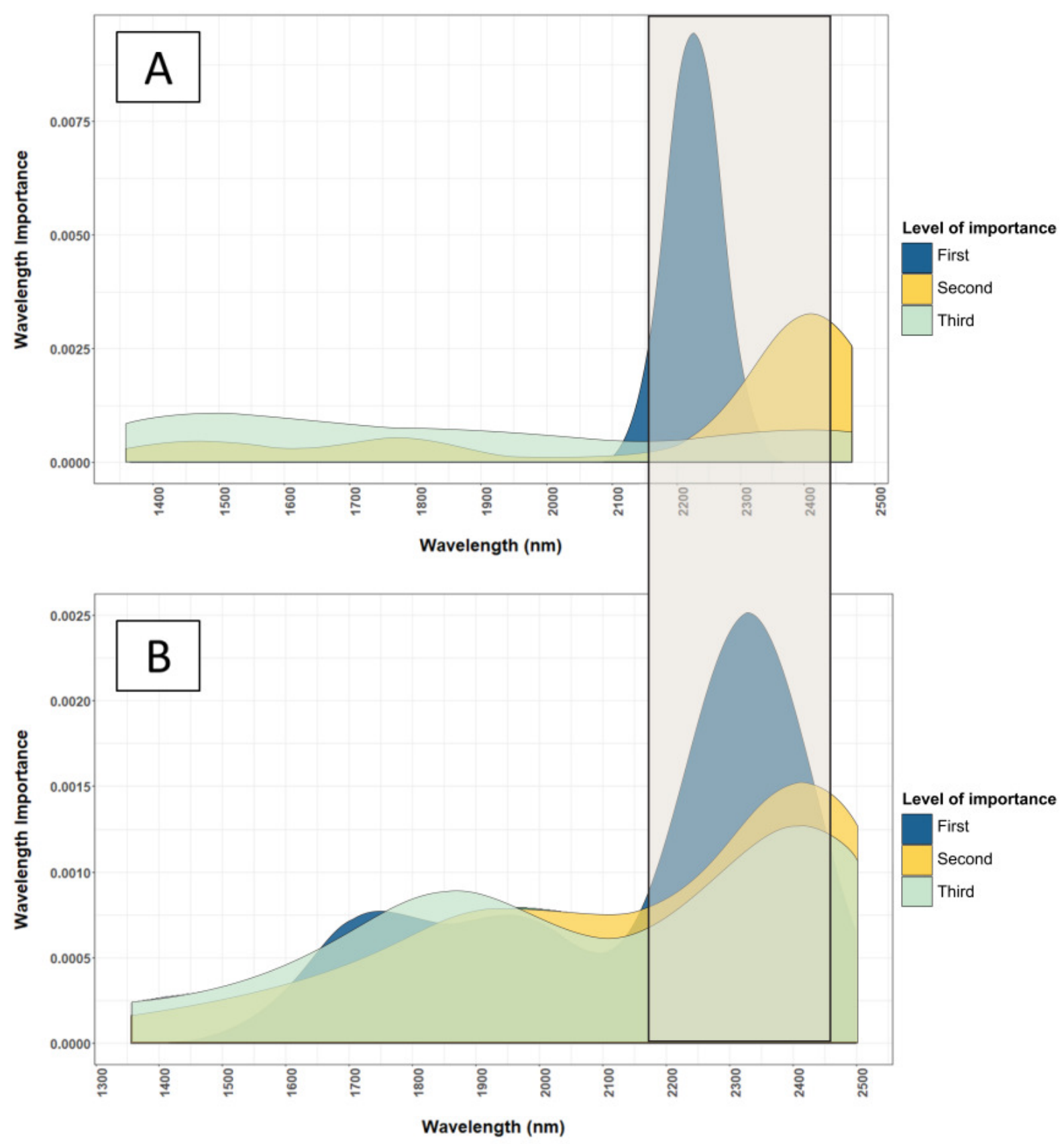


Figure 6

NIR reflectance spectra of fresh and dried, and ground cotton leaf samples.

Moisture affected regions (1400 and $1950 \mathrm{~nm}$ ) are highlighted. Fresh leaves have a lower NIR reflectance spectrum.

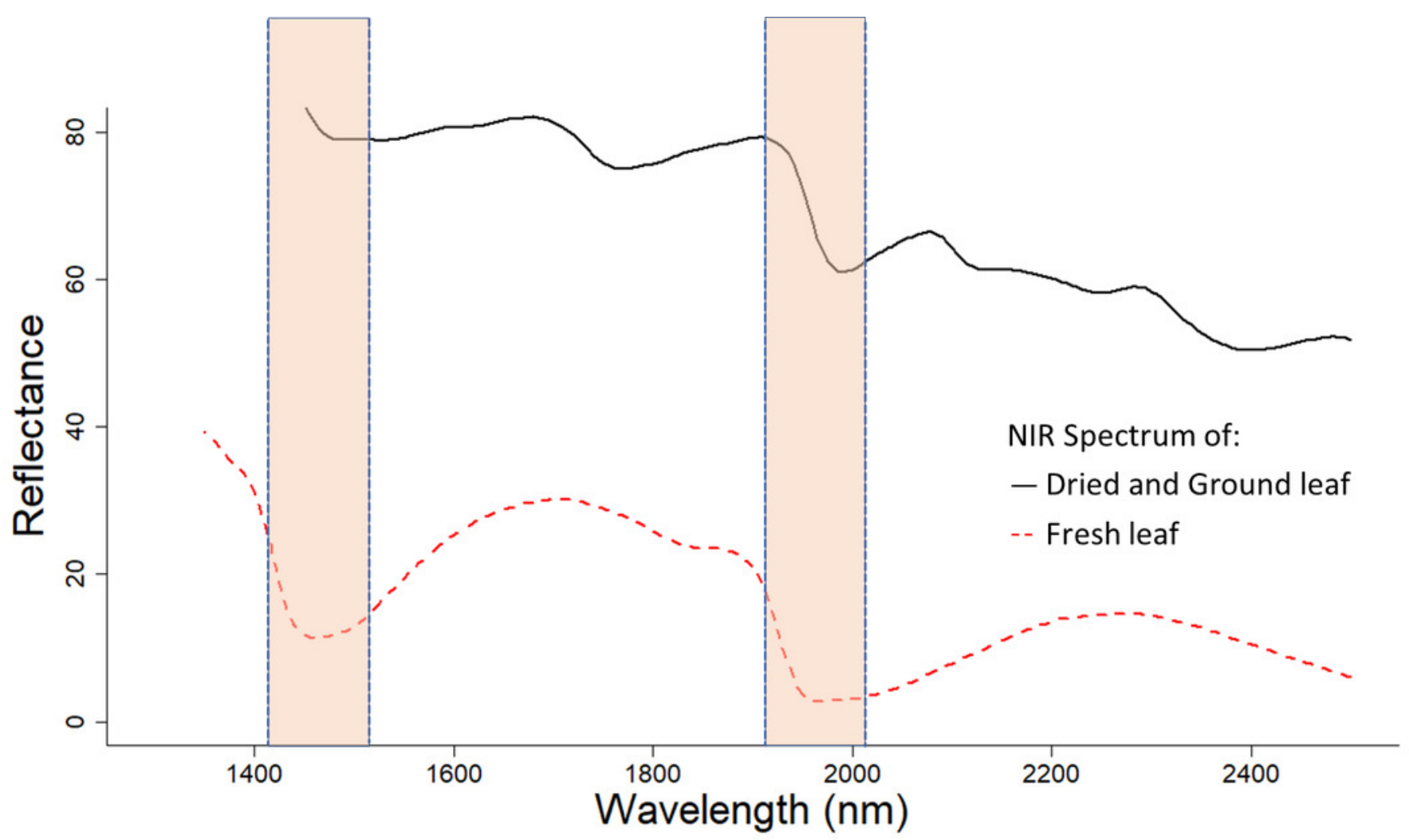




\section{Figure 7}

Comparison of important wavelenght used to determine the total $\mathrm{N}$ content of cotton leaves using NIRS models developed from dried and ground, and fresh and removed leaves.

(A) Important wavelength used to estimate total nitrogen content of dried and ground leaf samples. (B) Important wavelength used to estimate total nitrogen content of fresh and removed leaf samples. The dried and ground leaf models used wavelengths at $2200 \mathrm{~nm}$ $2450 \mathrm{~nm}$, where the fresh and removed leaf model used wavelengths at $1425 \mathrm{~nm}-2500 \mathrm{~nm}$. The level of importance shows the top three most important wavelengths used in the 50 iterations of the Cubist model to predict the leaf nutrients. The construction of the graph is explained in section 2.5 . 

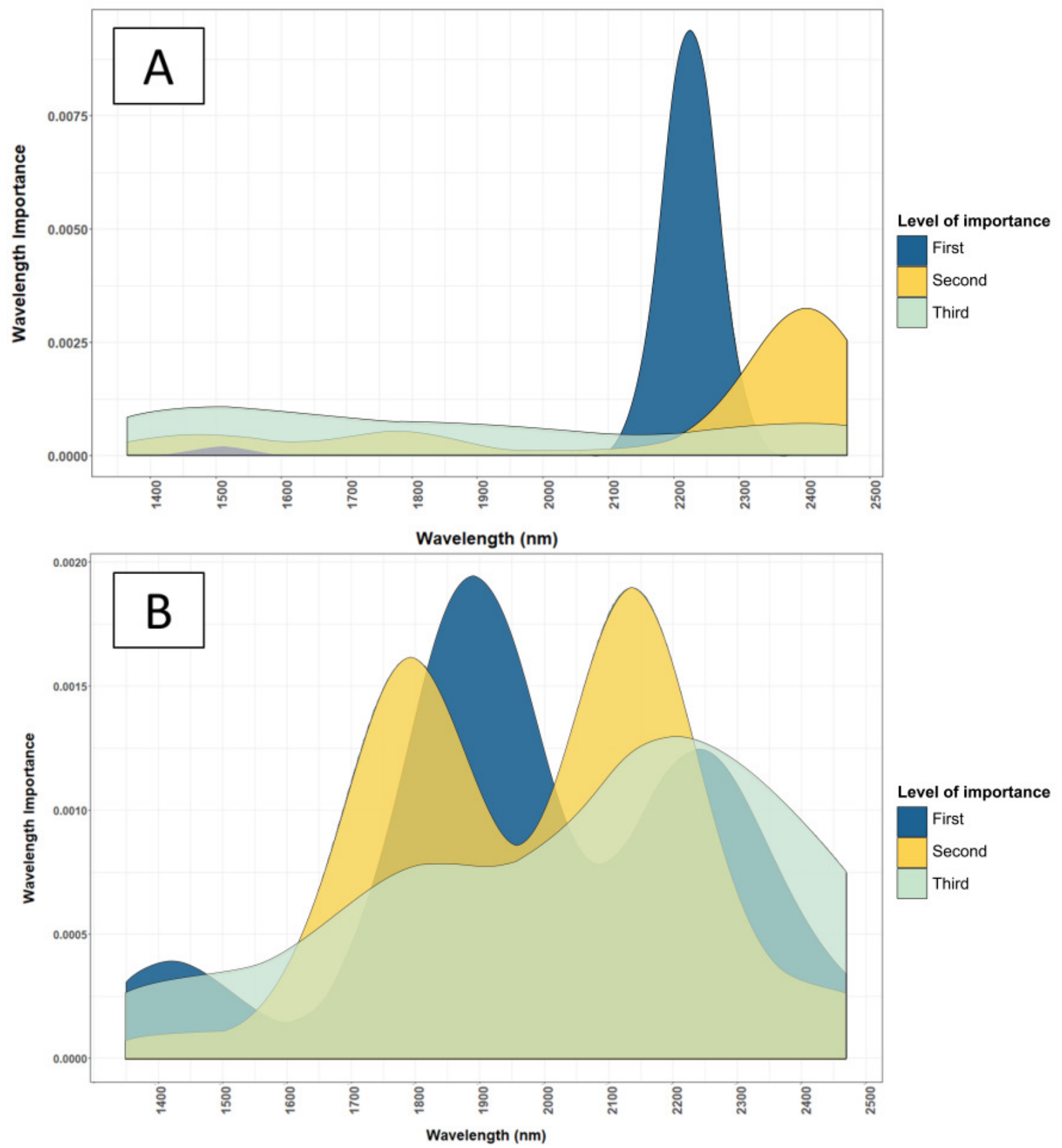


\section{Table $\mathbf{1}$ (on next page)}

Summary of the nutrient content values of the cotton leaf samples.

The summary includes the median value and range of the nutrients' content value of the cotton leaf samples $(n=375)$ that were used to establish the calibration. 
1

Macronutrient

\begin{tabular}{lcc}
\hline Nutrient & Median (\%) & Range (\%) \\
\hline Total Nitrogen & 3.59 & $1.53-5.49$ \\
Phosphorus & 0.36 & $0.14-0.87$ \\
Potassium & 1.58 & $0.69-4.23$ \\
Calcium & 4.23 & $2.04-7.26$ \\
Magnesium & 0.70 & $0.37-1.38$ \\
Sulfur & 1.00 & $0.57-3.09$ \\
Petiole Total $\mathrm{N}^{*}$ & 1.99 & $1.07-4.47$ \\
Nitrate-N & $764.06(\mathrm{mg} / \mathrm{kg})$ & $40.00-4611.38(\mathrm{mg} / \mathrm{kg})$ \\
\hline
\end{tabular}

Micronutrient

\begin{tabular}{lcc}
\hline Nutrient & Median $(\mathrm{mg} / \mathrm{kg})$ & Range $(\mathrm{mg} / \mathrm{kg})$ \\
\hline Iron & 184.27 & $73.65-900.80$ \\
Manganese & 86.21 & $27.50-367.80$ \\
Copper & 6.52 & $1.92-12.50$ \\
Zinc & 19.39 & $8.14-64.62$ \\
Molybdenum & 781.41 & $153.27-2937.57$ \\
Boron & 99.46 & $43.15-185.88$ \\
Chloride & 12300.00 & $6700-30000$ \\
Sodium & 1000.00 & $200-5300$ \\
\hline
\end{tabular}

${ }^{*}$ Only had 115 samples

3 


\section{Table 2 (on next page)}

Results of the paired t-test between the 75:25 split validation RMSE of the dried and ground cotton leaf and the fresh and removed cotton leaf macronutrient and micronutrient models that were constructed from the NIR spectra captured using the PhoneLab[

The results include the $p$-value of the paired t-test. The complete accuracy parameters of the dried and ground and fresh and removed calibrations are available in supplementary Table 4. 
1

\begin{tabular}{|c|c|c|c|c|}
\hline \multirow[t]{2}{*}{ Macronutrient } & Dried and Ground & $\begin{array}{l}\text { Fresh and } \\
\text { Removed }\end{array}$ & \multirow[t]{2}{*}{ P-value } & \multirow[t]{2}{*}{$\begin{array}{l}\text { Preferred Sample } \\
\text { Preparation }\end{array}$} \\
\hline & $\begin{array}{c}\text { Validation RMSE } \\
\text { (\%) }\end{array}$ & $\begin{array}{c}\text { Validation RMSE } \\
\text { (\%) }\end{array}$ & & \\
\hline Total Nitrogen & 0.21 & 0.29 & $<0.001$ & Dried and Ground \\
\hline Phosphorus & 0.09 & 0.09 & 0.066 & - \\
\hline Potassium & 0.37 & 0.37 & 0.867 & - \\
\hline Calcium & 0.36 & 0.53 & $<0.001$ & Dried and Ground \\
\hline Magnesium & 0.09 & 0.09 & 0.179 & - \\
\hline Sulfur & 0.19 & 0.32 & $<0.001$ & Dried and Ground \\
\hline Petiole Total $\mathbf{N}^{*}$ & 0.38 & 0.38 & 0.787 & - \\
\hline Nitrate- $\mathbf{N}^{+}$ & 685.52 & 713.09 & 0.567 & - \\
\hline \multicolumn{5}{|l|}{${ }^{*} \mathrm{n}=115$} \\
\hline \multicolumn{5}{|l|}{ + RMSE (mg/kg) } \\
\hline \multirow[t]{2}{*}{ Micronutrient } & Dried and Ground & Fresh and Removed & \multirow[t]{2}{*}{ P-value } & \multirow{2}{*}{$\begin{array}{l}\text { Preferred Sample } \\
\text { Preparation }\end{array}$} \\
\hline & $\begin{array}{c}\text { Validation RMSE } \\
\text { (mg/kg) }\end{array}$ & $\begin{array}{c}\text { Validation RMSE } \\
\text { (mg/kg) }\end{array}$ & & \\
\hline Iron & 64.2 & 76.29 & $<0.001$ & Dried and Ground \\
\hline Manganese & 44.14 & 45.59 & 0.225 & - \\
\hline Copper & 1.10 & 1.35 & $<0.001$ & Dried and Ground \\
\hline Zinc & 8.07 & 7.02 & 0.004 & Fresh and Removed \\
\hline Molybdenum & 203.98 & 255.47 & $<0.001$ & Dried and Ground \\
\hline Boron & 19.36 & 17.44 & $<0.001$ & Fresh and Removed \\
\hline Chloride & 2300 & 2700 & 0.009 & - \\
\hline Sodium & 400 & 500 & $<0.001$ & Dried and Ground \\
\hline
\end{tabular}

5 


\section{Table 3 (on next page)}

Result of the paired t-test between the 75:25 split validation RMSE of the fresh and removed cotton leaf and fresh and intact cotton leaf macronutrient and micronutrient models that were constructed from the NIR spectra captured using the PhoneLab[sup]TM

The results include the $p$-value of the paired t-test. The complete accuracy parameters of the dried and ground and fresh and removed calibrations are available in supplementary Table 5. 
1

\begin{tabular}{|c|c|c|c|c|}
\hline \multirow[t]{2}{*}{ Macronutrient } & Fresh and Removed & Fresh and Intact & \multirow[t]{2}{*}{ P-value } & \multirow{2}{*}{$\begin{array}{l}\text { Preferred Sample } \\
\text { Preparation }\end{array}$} \\
\hline & $\begin{array}{c}\text { Validation RMSE } \\
\text { (\%) }\end{array}$ & $\begin{array}{c}\text { Validation RMSE } \\
\text { (\%) }\end{array}$ & & \\
\hline Total Nitrogen & 0.26 & 0.28 & 0.035 & - \\
\hline Phosphorus & 0.11 & 0.11 & 0.509 & - \\
\hline Potassium & 0.44 & 0.41 & 0.028 & - \\
\hline Calcium & 0.63 & 0.56 & 0.005 & Fresh and Intact \\
\hline Magnesium & 0.11 & 0.12 & 0.089 & - \\
\hline Sulfur & 0.38 & 0.38 & 0.953 & - \\
\hline Petiole Total N & 0.34 & 0.31 & 0.015 & - \\
\hline Nitrate-N $\mathbf{N}^{+}$ & 832.85 & 772.09 & 0.116 & - \\
\hline
\end{tabular}

$2+$ RMSE (mg/kg)

3

\begin{tabular}{|c|c|c|c|c|}
\hline \multirow[t]{2}{*}{ Micronutrient } & \multirow{2}{*}{$\begin{array}{c}\text { Fresh and Removed } \\
\text { Validation RMSE } \\
\text { (mg/kg) }\end{array}$} & \multirow{2}{*}{$\begin{array}{c}\text { Fresh and Intact } \\
\text { Validation RMSE } \\
\text { (mg/kg) }\end{array}$} & \multirow[t]{2}{*}{ P-value } & \multirow{2}{*}{$\begin{array}{l}\text { Preferred Sample } \\
\text { Preparation }\end{array}$} \\
\hline & & & & \\
\hline Iron & 85.65 & 68.85 & 0.013 & - \\
\hline Manganese & 60.62 & 52.94 & $<0.001$ & Fresh and Intact \\
\hline Copper & 1.15 & 1.26 & 0.001 & Fresh and Removed \\
\hline Zinc & 9.76 & 9.06 & 0.186 & - \\
\hline Molybdenum & 176.38 & 166.22 & 0.200 & - \\
\hline Boron & 20.08 & 18.95 & 0.119 & - \\
\hline Chloride & 2800.00 & 2700.00 & 0.868 & - \\
\hline Sodium & 281.83 & 251.16 & 0.002 & Fresh and Intact \\
\hline
\end{tabular}

4 